\title{
BMJ Open Prevalence and associated factors of hypertension in selected urban and rural areas of Dhaka, Bangladesh: findings from SHASTO baseline survey
}

Mehedi Hasan (D) , ${ }^{1}$ Md Showkat Ali Khan, ${ }^{1}$ Ipsita Sutradhar, ${ }^{2}$ Md Mokbul Hossain, ${ }^{1}$ Moyazzam Hossaine, ${ }^{1}$ Yukie Yoshimura, ${ }^{3}$ Sohel Reza Choudhury, ${ }^{4}$ Malabika Sarker, ${ }^{2}$ Malay Kanti Mridha (D) ${ }^{1}$

To cite: Hasan M, Khan MSA, Sutradhar I, et al. Prevalence and associated factors of hypertension in selected urban and rural areas of Dhaka, Bangladesh: findings from SHASTO baseline survey. BMJ Open 2021;11:e038975. doi:10.1136/ bmjopen-2020-038975

- Prepublication history for this paper is available online. To view these files, please visit the journal online (http://dx.doi org/10.1136/bmjopen-2020038975).

Received 30 March 2020 Revised 16 0ctober 2020 Accepted 31 December 2020

Check for updates

(C) Author(s) (or their employer(s)) 2021. Re-use permitted under CC BY-NC. No commercial re-use. See rights and permissions. Published by BMJ.

For numbered affiliations see end of article.

Correspondence to Professor Malay Kanti Mridha; malay.mridha@bracu.ac.bd

\section{ABSTRACT}

Objective We implemented this study to report the prevalence and associated risk factors of hypertension among adult men and women aged $>30$ years residing in selected urban and rural areas of Dhaka division, Bangladesh.

Design Cross-sectional study.

Setting Two urban (Dhaka city north and Dhaka city south) and two rural (Narsinghdi and Gazipur district) areas of the Dhaka division.

Participants A total of 4856 male and female participants were included in the final analysis, of whom 2340 (48.2\%) were from urban and $2516(51.8 \%)$ were from rural areas.

Primary outcome Hypertension was the dependent variable for this study and was operationally defined as systolic blood pressure $\geq 140 \mathrm{~mm}$ of $\mathrm{Hg}$ and/or diastolic blood pressure $\geq 90 \mathrm{~mm}$ of $\mathrm{Hg}$, and/or persons with already diagnosed hypertension.

Results The overall prevalence of hypertension was $31.0 \%$, and the prevalence was higher among urban participants (urban: $36.9 \%$, rural: $30.6 \%$ ). Age (across all categories), female (urban—adjusted OR (AOR): 1.3, $95 \% \mathrm{Cl}: 1.0$ to 1.5 and rural-AOR: $1.7,95 \% \mathrm{Cl}: 1.4$ to $2.1)$ ), higher educational status (urban-AOR: $1.7,95 \% \mathrm{Cl}$ : 1.3 to 2.2 and rural—AOR: $2.1,95 \% \mathrm{Cl}: 1.5$ to 3.1 ), inadequate physical activity (urban-AOR: $1.3,95 \% \mathrm{Cl}$ : 1.0 to 1.7 and rural-AOR: $1.5,95 \% \mathrm{Cl}: 1.2$ to 1.9 ) and overweight/obesity (urban-AOR: $2.7,95 \% \mathrm{Cl}: 2.1$ to 3.3 and rural—AOR: $2.1,95 \% \mathrm{Cl}: 1.7$ to 2.5$)$ were associated with hypertension in both urban and rural areas. Women who were not currently married during the survey had higher odds of hypertension only in the rural areas (rural—AOR: $1.8,95 \% \mathrm{Cl}: 1.3$ to 2.4), and respondents who were not working during the survey had higher odds of hypertension only in the urban areas (AOR: $1.7,95 \% \mathrm{Cl}$ : 1.0 to 2.6 ).

Conclusion Since the prevalence of hypertension was high in urban and rural areas, the government of Bangladesh should consider implementing hypertension prevention programmes focusing young population of Dhaka division. In addition, early screening programmes and management of hypertension need to be strengthened for people with hypertension in both the areas.

\section{Strengths and limitations of this study}

- Lack of studies reporting an urban-rural difference in prevalence of hypertension and its associated factors using recent data.

- This study used baseline data from the Strengthening Health Systems through Organizing Communities project, which was conducted in 2018 and included data on fruits and vegetable consumption, physical activity and tobacco consumption.

- As it is a cross-sectional study, we could not establish causality due to the lack of temporal relationship.

- This study was conducted in two urban and two rural sites of the Dhaka division. Therefore, this study's findings might not be possible to generalise for the whole of Bangladesh, especially in the regions where the geographical and sociocultural variance is more compared with the Dhaka division.

\section{INTRODUCTION}

Hypertension is a global public health concern and one of the major clinical risk factors for cardiovascular diseases like stroke, heart failure, coronary artery disease and kidney diseases. ${ }^{1}$ According to the WHO, 1.13 billion people have hypertension globally. ${ }^{2}$ As per a study published in 2005, the number of patients with hypertension is projected to be 1.56 billion by 2025 . $^{3}$ Among the patients with hypertension, two-thirds are from low-and middle-income countries. ${ }^{2}$ The prevalence of hypertension in low-and middle-income countries was $32.3 \%$, and the prevalence was $29.4 \%$ in South Asia. ${ }^{4}$

Currently, Bangladesh is going through an epidemiological transition where disease burden is shifting from communicable diseases to non-communicable diseases (NCDs). ${ }^{5}$ Bangladesh STEPS Survey 2018 reported that the prevalence of hypertension among Bangladeshi adults is $25.2 \%{ }^{6}$ On top 
of that, the prevalence of NCD risk factors is also high in Bangladesh. The same study also revealed that $43.7 \%$ of Bangladeshi people consumed any form of tobacco, $89.6 \%$ people did not consume adequate fruits and vegetable ( $\geq 5$ servings fruits and vegetableper day), $29.1 \%$ people did not perform adequate physical activities $\_\geq 600$ metabolic equivalents (METs) per week) and 25.8\% people were either overweight or obese. ${ }^{6}$

The prevalence of hypertension can vary among populations according to continents, countries, regions, age, sex and race. ${ }^{7-9}$ Even within the country, the prevalence can vary based on households' location (urban vs rural). Though several studies have reported that the prevalence is higher in urban areas than in rural areas, the gap is gradually decreasing as the prevalence of hypertension is increasing rapidly in rural areas. ${ }^{10-13}$ Therefore, we need evidence about the current distribution of hypertension and its associated risk factors in urban and rural areas to formulate cost-effective strategies for successful prevention and control of hypertension in developing countries like Bangladesh. However, we could not find enough literature based on recent data that reported the rural-urban variation in prevalence and associated risk factors of hypertension in Bangladesh. In Bangladesh, we only found one study that reported the prevalence and determinants of hypertension in urban and rural areas. However, the study used data from the Bangladesh Demographic and Health Survey 2010, which did not include data on behavioural risk factors e.g., fruits and vegetable consumption, physical activity and tobacco consumption. ${ }^{14}$ Therefore, we conducted this analysis to measure the difference in prevalence of hypertension and its associated risk factors in urban and rural areas of Dhaka division using data from the Strengthening Health Systems through Organizing Communities (SHASTO) project baseline survey. The government of Bangladesh, together with the Japan International Cooperation Agency (JICA), is implementing the SHASTO project for improving NCD, maternal, newborn and child health services in an integrated manner in Dhaka city and Narsinghdi district.

\section{MATERIALS AND METHODS}

\section{Study population and site}

We conducted a cross-sectional survey among adult men and women aged $>30$ years residing in selected urban and rural sites of Dhaka division. SHASTO project aimed to provide NCD interventions only to $>30$ years old individuals. In our study, Dhaka city north and Dhaka city south represented urban sites, and Narsingdi and Gazipur districts represented rural sites. From Dhaka city north and Dhaka city south, both slum and non-slum areas were included. The study was conducted between February 2018 and May 2018.

\section{Sample size}

The sample size was calculated using the prevalence of tobacco consumption (51\%) obtained from the NCD Risk
Factors Survey 2010. The minimum sample size was 384, considering a 5\% margin of error and a $95 \%$ confidence level. Since the randomisation units were cluster in rural and urban areas, we inflated the sample size by a design effect of 1.5. Moreover, we wanted to generate separate estimates for women and men. Accordingly, a minimum of $(384 \times 2 \times 1.5)$ or 1152 respondents were required from each study site. The final sample size was 1268 , considering the $10 \%$ non-response rate. Finally, we aimed to collect data from 1268 women and men in each study site with a total sample size of $(1268 \times 4)$ or 5072 from four sites. In reality, we could collect complete data from 4856 respondents (male-2425 and female-2431).

\section{Sampling technique}

Under the SHASTO project, the intervention was planned to implement in one urban and one rural area of the Dhaka division to prevent and control NCDs. To compare the outcome of the intervention during the subsequent surveys, we also included one control site in each of the urban and rural areas. Multistage cluster sampling techniques were used for selecting the participants, and separate sampling techniques were applied for urban and rural settings. In the SHASTO project, for the rural sites, Shibpur subdistrict of Narsingdi district was selected for providing intervention, and the Kaliganj subdistrict of the Gazupur district was selected as control. There are 38 community clinics in Shibpur, and 31 community clinics in Kaliganj. Three community clinics (primary healthcare facility in rural settings providing services to about 6000 people) were selected randomly from all community clinics in each rural subdistrict. According to the health facility registry of Bangladesh, there are 18 urban dispensaries (primary healthcare facilities in urban settings) in the Dhaka north and Dhaka south city corporations. In SHASTO project, Dhaka city north was selected for intervention and Dhaka city south was selected as control. We randomly selected one urban dispensary from each of these city corporations. For each of the intervention and control sites in urban areas, one non-slum area and one slum were selected. Household listing was carried out in the selected rural and urban clusters. Separate sampling frames for male and female respondents aged $>30$ years were developed for each cluster from the household listing data. The study participants were selected randomly from these sampling frames using Microsoft Excel 2013. Not more than one male and/or female participant was selected from the same household.

\section{Study tool and supporting materials}

A modified version of the STEPS Questionnaire developed by the WHO was used for data collection. The questionnaire was divided into four segments: sociodemographic, behavioural risk factors, metabolic risk factors and physical measurements. Five different show cards (salty food, fruits and vegetable, tobacco products, vigorous physical activity, and moderate physical activity) were used by the data collectors so that the respondents 
could easily understand the questions. In addition, $200 \mathrm{~mL}$ measurement bowls equivalent to one serving of uncooked fruits/vegetable and two servings of cooked fruits/vegetable were used to collect data on fruits and vegetable consumption.

\section{Dependent variable}

Hypertension was the dependent variable for this study. Participants having systolic blood pressure $\geq 140 \mathrm{~mm}$ of $\mathrm{Hg}$, and/or diastolic blood pressure $\geq 90 \mathrm{~mm}$ of $\mathrm{Hg}$, and/ or persons with already diagnosed hypertension were considered hypertensive.

\section{Independent variable}

In our study, a wide range of sociodemographic (age, gender, educational status, marital status, occupation, religion, family type, and household income), behavioural (fruit and vegetable consumption, salt consumption, physical activity and tobacco consumption) and metabolic factor (overweight/obesity) were considered as independent variables. We selected independent variables based on the published literature and from the variables collected in our study.

\section{Data collection}

Data collection was performed by conducting face-toface interviews, and physical measurements were taken following standard operating procedures developed based on anthropometric indicators measurement guide. ${ }^{15}$ For physical measurements (height, weight and blood pressure), adequate privacy was ensured. Male and female data collectors measurements of male and female respondents, respectively. Data collection was performed using tablet computers.

Blood pressure of eligible participants was measured using the Omron HEM 7120 automatic digital blood pressure machine. Before taking the measurement, the participants were asked to rest for 15 minutes and placed his/her left arm on a table with the palm facing upward. The data collectors rolled up the clothes on their arms in a way that did not exert pressure on the arm. An appropriately sized cuff was used $1.2-2.5 \mathrm{~cm}$ above the elbow joint and wrapped snugly onto the arm, keeping it at the same level of the heart during the measurement. Blood pressure was measured two times at 3-minute interval for each participant, and the third measurement was taken if the difference between the first and second measurement was more than $10 \mathrm{~mm}$ of $\mathrm{Hg}$. The average of the two closest measurements was used to ascertain blood pressurewhile categorizing a participant as hypertensive.

A portable height measuring board was used to measure the height of the respondents. Height was measured after removing footwear and headgear that might give a false reading. Height was measured two times for each participant, and the third measurement was taken if the difference between the first and second measurement was more than $0.5 \mathrm{~cm}$. The average of the two closest measurements was used to calculate height.
In this study, the TANITA UM070 measurement scale was used to measure the study participants' weight. Weight was measured after taking mobiles, wallets and coins out of their pockets, and removing shoes, slippers, sandals, socks and belts that might give an inaccurate measurement. Interviewers ensured that the scales were placed on a firm and flat surface. We measured weight two times for each participant, and the third measurement was taken if the difference between the first and second measurement was more than $0.1 \mathrm{~kg}$. The average of the two closest measurements was used to calculate weight.

\section{Quality control}

During the design phase, a multistage cluster sampling technique was adopted to minimise potential selection bias. Interview sessions and physical measurements were performed by experienced and extensively trained data collectors to avoid information bias. At the field level, data collectors were monitored and supervised by field supervisors and quality control officers. The field supervisors observed data collection sessions and gave regular feedback. The quality control officer reinterviewed 5\% of the respondents using a quality control questionnaire and retook anthropometric measurements of $5 \%$ of the respondents. Calibration of the necessary instruments (blood pressure machine, height scale, weight scale) was done every morning before the initiation of fieldwork.

\section{Data analysis}

After completing data collection, data were downloaded from the server, and the CSV file was converted into a DTA file format. Subsequently, all the variable names and labels were checked, and data were cleaned. Some observations (income $=19$, age $=33$, education $=2$, salt $=3$ and hypertension=17) were removed from the analysis because of having missing value. Recoding of values and categorisation of variables were done to facilitate further analysis. Descriptive analysis was performed and presented as frequency and percentage. The weighted prevalence of hypertension was reported across all socioeconomic, behavioural and metabolic strata. A $\mathrm{X}^{2}$ test was performed to see the difference between hypertension prevalence across socioeconomic, behavioural and metabolic strata. Both the adjusted and unadjusted analyses were performed to find out the associated factors of hypertension. Any variable with a $p$ value of $>0.2$ was dropped from the adjusted analysis. ${ }^{16}$ A forward stepwise approach was used to select the final model. ${ }^{17}$ Multicollinearity was checked among the independent variables by observing the variance inflation factor (VIF) and VIF $>5$ indicated multicollinearity. ${ }^{18}$ We did not find multicollinearity between the explanatory variables. At $95 \%$ level of confidence, both the crude OR (COR) and adjusted OR (AOR) were calculated and reported for the independent variable. The factors were considered associted if $\mathrm{p}<0.05$. Data were analysed using Stata V.15 (StataCorp), ${ }^{19}$ and results were presented in tables and figures. 


\section{Ethical consideration}

Informed written consent was taken from each participant for the interview and physical measurements after clarifying the study objective, voluntary nature of their participation and rights of withdrawal at any time during the interview. Confidentiality was ensured by not disclosing the identity of respondents to any third party. The completed questionnaires were given a unique ID to maintain the anonymity of the respondents. In addition, participants had the right to withdraw from the study anytime without any prejudice or penalty. Furthermore, participants did not receive any financial incentive or compensation for participating in the study. All the participants with systolic blood pressure more than $\geq 140 \mathrm{~mm}$ of $\mathrm{Hg}$ or diastolic blood pressure $\geq 90 \mathrm{~mm}$ of $\mathrm{Hg}$ were referred to the nearest government healthcare facility to confirm the diagnosis. In addition, pre-diagnosed hypertensive participants with high systolic blood pressure $(\geq 140 \mathrm{~mm}$ of $\mathrm{Hg})$ or high diastolic blood pressure $(\geq 90 \mathrm{~mm}$ of $\mathrm{Hg}$ ) were referred to the nearest government health facility even if they were taking antihypertensive medication.
Patient and public involvement

No patient was involved.

\section{RESULTS}

A total of 4856 male and female participants aged $>30$ years were included in the final analysis, of whom 2340 $(48.2 \%)$ were from urban and $2516(51.8 \%)$ were from rural areas (figure 1).

Table 1 describes the sociodemographic characteristics of the study participants separately for urban and rural areas. A higher proportion of the study participants belonged to 31-39 years age group. Almost equal proportion of male (urban: $49.9 \%$ vs rural: $50.0 \%$ ) and female respondents (urban: $50.1 \%$ vs rural: $50.0 \%$ ) participated in this study. In the no education and higher education group, a higher proportion of the participants were from urban residence (no education-urban: $35.3 \%$ vs rural: $33.2 \%$; higher education-urban: $21.1 \%$ vs rural: $7.0 \%$ ). Almost all of our study participants were married (89.3\%), currently working (94.3\%) and Muslims by faith (94.7\%); and the urban-rural difference was negligible for these

Household visited: 4806

(Urban: 2250 and Rural: 2556)

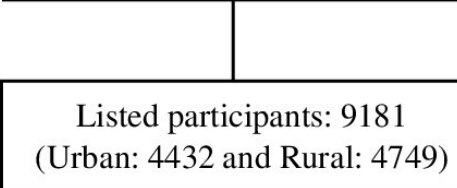

Maximum of one male and/or one female participants were randomly selected from each household

Total participants: 8170

(Urban: 3969 and Rural: 4201)

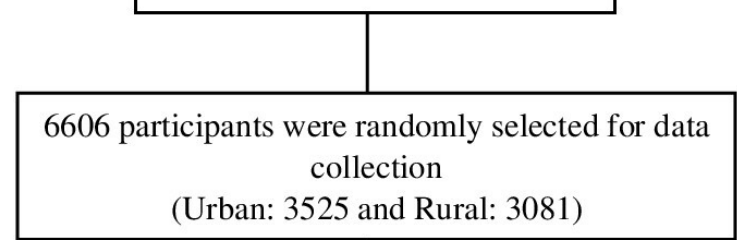

4930 particiapnts were interviewed and measured for anthropometric data

(Urban: 2389 and Rural: 2541)

[1268 participants were required from each cluster]

74 data points were removed (income $=19$, age $=33$, education $=2$, salt $=3$, and hypertension $=17$ ) for having missing value.

4856 data points were included in the analysis (urban:2340, rural:2516)

Figure 1 Flowchart showing selection of study participants. 
Table 1 Sociodemographic, behavioural and metabolic characteristics of study respondents stratified by urban and rural areas

\begin{tabular}{|c|c|c|c|}
\hline & Total & Urban & Rural \\
\hline & $\mathrm{N}=4856$ & $\mathrm{~N}=2340$ & $\mathrm{~N}=2516$ \\
\hline Variables & n (\%) & n (\%) & n (\%) \\
\hline \multicolumn{4}{|l|}{ Age (years) } \\
\hline $31-39$ & $1796(37.0)$ & $976(41.7)$ & $820(32.6)$ \\
\hline $40-49$ & $1326(27.3)$ & 677 (28.9) & $649(25.8)$ \\
\hline $50-59$ & 967 (19.9) & $415(17.7)$ & $552(21.9)$ \\
\hline$\geq 60$ & 767 (15.8) & $272(11.6)$ & 495 (19.7) \\
\hline \multicolumn{4}{|l|}{ Gender } \\
\hline Male & 2425 (49.9) & $1168(49.9)$ & $1257(50.0)$ \\
\hline Female & $2431(50.1)$ & $1172(50.1)$ & $1259(50.0)$ \\
\hline \multicolumn{4}{|l|}{ Education status } \\
\hline No education & $1660(34.2)$ & $826(35.3)$ & $834(33.2)$ \\
\hline Primary education & $1302(26.8)$ & $510(21.8)$ & $792(31.5)$ \\
\hline Secondary education & $1226(25.3)$ & $511(21.8)$ & 715 (28.4) \\
\hline Higher education & $668(13.8)$ & $493(21.1)$ & $175(7.0)$ \\
\hline \multicolumn{4}{|l|}{ Marital status } \\
\hline Currently married & $4338(89.3)$ & $2103(89.9)$ & $2235(88.8)$ \\
\hline Others* & $518(10.7)$ & $237(10.1)$ & $281(11.2)$ \\
\hline \multicolumn{4}{|l|}{ Occupation status } \\
\hline Currently working & 4579 (94.3) & $2204(94.2)$ & $2375(94.4)$ \\
\hline Not working & $277(5.7)$ & $136(5.8)$ & $141(5.6)$ \\
\hline \multicolumn{4}{|l|}{ Religion } \\
\hline Islam & $4596(94.7)$ & 2152 (92.0) & $2444(97.1)$ \\
\hline Others $†$ & $260(5.4)$ & $188(8.0)$ & $72(2.9)$ \\
\hline \multicolumn{4}{|l|}{ Family type } \\
\hline Joint & 1125 (23.2) & $415(17.7)$ & $710(28.2)$ \\
\hline Nuclear & 3731 (76.8) & 1925 (82.3) & $1806(71.8)$ \\
\hline \multicolumn{4}{|l|}{ Household income } \\
\hline$<$ Below median & $2418(49.8)$ & 879 (37.6) & $1539(61.2)$ \\
\hline$\geq$ Above median & 2438 (50.2) & $1461(62.4)$ & $977(38.8)$ \\
\hline \multicolumn{4}{|l|}{ Fruits and vegetable consumption } \\
\hline$\geq 5$ servings per day & $991(20.4)$ & $221(9.4)$ & $770(30.6)$ \\
\hline$<5$ servings per day & $3865(79.6)$ & $2119(90.6)$ & $1746(69.4)$ \\
\hline \multicolumn{4}{|l|}{ Added salt in diet } \\
\hline Yes & $4323(89.0)$ & 2104 (89.9) & 2219 (88.2) \\
\hline No & $533(11.0)$ & $236(10.1)$ & $297(11.8)$ \\
\hline \multicolumn{4}{|l|}{ Physical activity } \\
\hline Adequate (MET >600 per week) & $3954(81.4)$ & $1921(82.1)$ & $2033(80.8)$ \\
\hline Inadequate (MET <600 per week) & $902(18.6)$ & $419(17.9)$ & $483(19.2)$ \\
\hline \multicolumn{4}{|l|}{ Tobacco consumption } \\
\hline Yes & $2385(49.1)$ & $1022(43.7)$ & $1363(54.2)$ \\
\hline No & $2471(50.9)$ & $1318(56.3)$ & $1153(45.8)$ \\
\hline \multicolumn{4}{|l|}{ Overweight or obese (Asian cut-off) } \\
\hline No & $2248(46.6)$ & $813(35.1)$ & $1435(57.2)$ \\
\hline Yes & $2576(53.4)$ & $1501(64.9)$ & $1075(42.8)$ \\
\hline
\end{tabular}

*Never married, widows, divorced and separated.

tHindu, Christian, Buddhist and others.

fFor overweight or obesity, total number of observations is different from the other variables since some participants refused to give the measurements. MET, metabolic equivalent. 
variables. The majority of the urban and rural participants (urban: 90.6 vs rural: 69.4\%) consumed less than five servings of fruits and vegetable per day; and added salt while taking meals (urban: $89.9 \%$ vs rural: $88.2 \%$ ); performed adequate physical activity (urban: $82.1 \%$ vs rural: $80.8 \%$ ). A higher proportion of rural participants consumed any form of tobacco than their rural counterparts (urban: 43.7 vs rural; 54.2\%). However, a higher proportion of urban participants were overweight or obese than rural participants (urban: $64.9 \%$ vs rural: $42.8 \%$ ).

Table 2 demonstrates the prevalence of hypertension across all sociodemographic, behavioural and metabolic characteristics separately for urban and rural areas. Compared with their rural counterparts, the prevalence of hypertension was significantly higher among urban residents in all age categories except for those in the $\geq 60$ years of age group. We also observed that prevalence of hypertension was significantly higher among urban men compared with rural men (urban: $34.4 \%$ vs rural: $22.8 \%$, $\mathrm{p}<0.01)$, though the urban-rural difference was not significant in the case of women (urban: $39.4 \%$ vs rural: $38.0 \%, \mathrm{p}=0.4009)$. In case of education, the urban-rural difference in hypertension prevalence was much higher $(>10 \%)$ among those who received secondary education (urban: $39.6 \%$ vs rural: $27.4 \%$, $\mathrm{p}<0.01$ ) and higher education i.e. higher than secondaary (urban: $49.2 \%$ vs rural: $38.5 \%, \mathrm{p}<0.01)$. Among the participants who consumed adequate fruits and vegetables ( $\geq 5$ servings/day) (urban: $43.0 \%$ vs rural: $28.1 \%, \mathrm{p}<0.05)$, consumed added salt (urban: $36.4 \%$ vs rural: $29.6 \%$ ) and performed adequate physical activity (urban: $35.0 \%$ vs rural: $27.6 \%, \mathrm{p}<0.05$ ), hypertension prevalence was significantly higher among urban residents than their rural counterparts. For occupational status, religion and family type, participants from urban areas had higher prevalence of hypertension across all strata. This study also revealed that the prevalence of hypertension was significantly higher among overweight or obese urban residents than their counterparts in rural areas (urban: $44.1 \%$ vs rural: $38.6 \%, \mathrm{p}<0.05$ ).

We observed that almost two-thirds of participants with hypertension knew their hypertensive status; out of those who were aware of their status, $58.9 \%$ sought health care. Though most of the people $(81.7 \%)$ with hypertension who sought care took medication for hypertension, $39.7 \%$ of them had uncontrolled hypertension. On the other hand, among the newly diagnosed participants with hypertension, $78.8 \%$ had stage-1 hypertension and 21.2\% had stage-2 hypertension (figure 2).

Table 3 describes the associated factors associated with hypertension along with COR and AOR in urban and rural areas. It was revealed from our study that the odds of hypertension had a significant association with age in both rural and urban areas, and the magnitude of this association was greater in urban areas. In rural settings, the odds of hypertension gradually increased with increased age. In contrast, these odds slightly decreased in urban settings after completion of the fifth decade of life. In both urban (AOR: 1.3; 95\% CI: 1.0 to 1.5) and rural settings $(\mathrm{AOR}=1.7 ; 95 \% \mathrm{CI}$ : 1.4 to 2.1 ), women had significantly higher odds of being hypertensive than their male counterparts. Among urban residents, those who received secondary (AOR: 1.6 ; 95\% CI: 1.2 to 2.0 ) or higher education (AOR: 1.7; 95\% CI: 1.3 to 2.2) had significantly higher odds of hypertension compared with those who received no education, though, in case of rural participants, a similar finding was observed only for those who received higher education (AOR: 2.1; 95\% CI: 1.5 to 3.1). Our study also revealed that rural participants who were not currently married had significantly higher odds of having hypertension (AOR: 1.8; 95\% CI: 1.3 to 2.4) than the married participants, and urban participants who were not working had significantly higher odds of hypertension (AOR: 1.7; 95\% CI: 1.0 to 2.6) than the working participants. This study revealed that both the urban (AOR: 1.3; 95\% CI: 1.0 to 1.7) and rural (AOR: 1.5; 95\% CI: 1.2 to 1.9 ) participants who performed inadequate physical activity had significantly higher odds of hypertension compared with those who performed adequate physical activity. Similarly, overweight or obese participants from both urban (AOR: 2.7; 95\% CI: 2.1 to 3.3) and rural (AOR: 2.1; 95\% CI: 1.7 to 2.5) areas had significantly higher odds of being hypertensive compared with those who were not overweight or obese. We also observed that tobacco consumption was a protective factor for developing hypertension in both urban (AOR: 1.3; $95 \%$ CI: 1.0 to 1.6 ) and rural settings (AOR: 1.4; $95 \%$ CI: 1.2 to 1.7$)$.

\section{DISCUSSION}

In our study, we observed that prevalence of hypertension was high among $>30$ year old participants in both rural and urban areas. For most of the sociodemographic, behavioural and metabolic strata, the prevalence of hypertension was higher among the participants from urban areas. In both rural and urban areas, odds of being hypertensive were found positively associated with age, gender, higher educational status, inadequate physical activity, and overweight/obesity; while a negative association was observed for tobacco consumption. Currently married women had higher odds of being hypertensive only in rural areas; and participants who were not working during the survey had higher odds of hypertension only in the urban area.

\section{Prevalence of hypertension}

In our study, we reported that the overall weighted prevalence of hypertension was $31.0 \%$, which was higher than that reported in the WHO STEPS Survey, Bangladesh $2018(25.2 \%)$. This difference could be explained by the age difference of study participants between these two studies. In our study, the prevalence of hypertension was reported for $>30$-year-old adults; on the other hand, the STEPS Survey included respondents aged $\geq 18$ years old. ${ }^{6}$ The hypertension prevalence obtained from our study was slightly lower than the prevalence reported by the authors 
Table 2 Prevalence of hypertension across all sociodemographic, behavioural and metabolic characteristics stratified by urban and rural areas

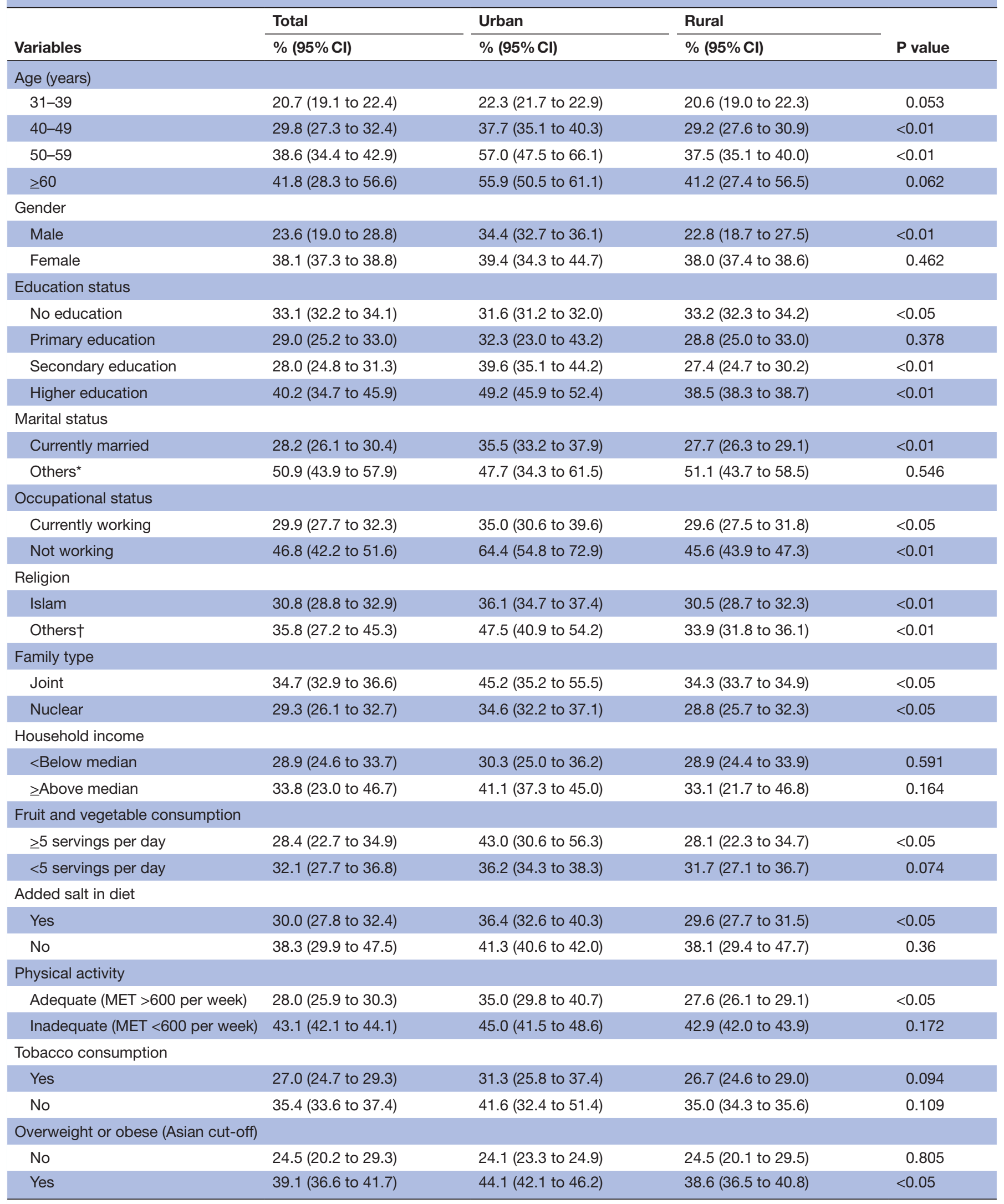

*Never married, widows, divorced and separated.

†Hindu, Christian, Buddhist and others.

MET, metabolic equivalent. 


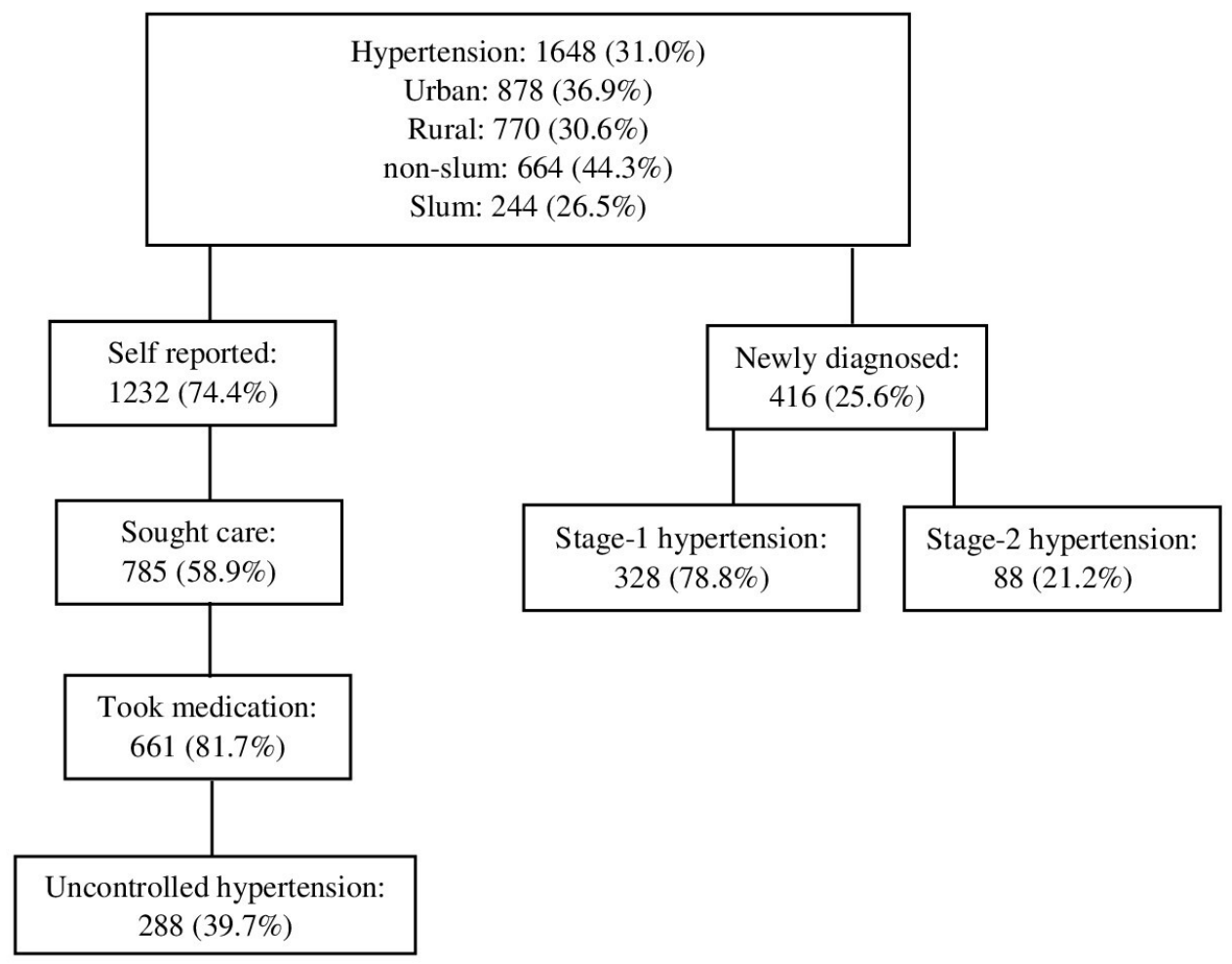

Figure 2 Hypertension, care seeking,medication and uncontrolled hypertension.

of a study that used Bangladesh Demographic and Health Survey 2011 data. ${ }^{20}$ The use of different methodologies, different study participants as well as geographical, sociocultural and genetic variation prevailing among these settings might explain this discrepancy. We also reported a higher prevalence of hypertension among urban participants compared with their rural counterparts (urban: $36.9 \%$ vs rural: $30.6 \%$ ). A similar finding was reported in a previously published Bangladeshi study, in which a higher prevalence of hypertension in urban settings was observed (urban: $32.6 \%$, rural: $23.6 \%$ ). ${ }^{14}$ Moreover, we found a significant urban-rural difference in hypertension prevalence for men, where urban men had a higher prevalence of hypertension than their rural counterparts. However, for women, the urban-rural difference was not significant. The WHO STEPS Survey also (2018) reported a similar finding. ${ }^{6}$ It is evident that urbanisation allows more and more people to adopt a sedentary lifestyle, ${ }^{21} 22$ consume more calorie-dense food, ${ }^{23} 24$ watch television, browse internet during leisure time ${ }^{25}$ and lead a stressful life, ${ }^{26}$ and all these factors increase the risk of developing hypertension and other cardiovascular diseases. ${ }^{27-29} \mathrm{We}$ found that urban residents who consumed adequate fruits and vegetables ( $\geq 5$ servings) had a higher prevalence of hypertension than their rural counterparts. Also, the prevalence of hypertension was higher among urban respondents who performed adequate physical activities (600 $\geq$ MET per week) compared with their rural counterparts. This finding might be explained by the fact that, in urban Bangladesh, individuals mostly from well-off families can purchase fruits and vegetables regularly. ${ }^{30} 31$ Moreover, these individuals also can afford gymnasium facilities and thus can perform regular physical activity. ${ }^{3233}$ Because of their high purchasing power, it is quite possible that they consume a higher quantity of other unhealthy food items (food rich in carbohydrate and saturated fat, high salt containing food items like processed meat and junk food) and thus become more prone to hypertension in developing countries like Bangladesh. The effect of urbanisation and associated factors on hypertension may be so strong that they cannot be mitigated even by healthy behaviour, for example, fruit and vegetable consumption and physical activity.

\section{Associated factors of hypertension}

We observed that age was positively associated with hypertension in both rural and urban areas. This finding is in accordance with the findings from previous studies conducted in Bangladesh, India and Pakistan, in which age was reported as one of the major determinants of hypertension. ${ }^{34-36}$ We also found a dose-response relationship between age and hypertension among rural participants, meaning the odds of hypertension increased with increased age. A similar finding was reported by a recently published study that used Bangladesh Demographic and Health Survey data. ${ }^{14}$ Interestingly, our study revealed that the odds of hypertension among urban participants increased with age initially; however, the odds of hypertension slightly decreased after crossing the fifth decade of life ( $\geq 60$ years). This finding might be attributable to the fact that the cause-specific mortality rate due to cardiovascular diseases is higher among the elderly population residing in urban areas than their counterparts living in rural areas (age-adjusted death rates: 
Table 3 Associated risk factors of hypertension with crude OR (COR) and adjusted OR (AOR) stratified by urban and rural areas

\begin{tabular}{|c|c|c|c|c|c|c|c|c|}
\hline \multirow[b]{2}{*}{ Variable } & \multicolumn{4}{|l|}{ Urban } & \multicolumn{4}{|l|}{ Rural } \\
\hline & COR & $95 \% \mathrm{Cl}$ & AOR & $95 \% \mathrm{Cl}$ & COR & $95 \% \mathrm{Cl}$ & AOR & $95 \% \mathrm{Cl}$ \\
\hline \multicolumn{9}{|l|}{ Age (years) } \\
\hline $40-49$ & $2.1^{\star \star \star}$ & 1.7 to 2.6 & $2.3^{\star \star \star}$ & 1.8 to 2.8 & $1.7^{\star \star \star}$ & 1.3 to 2.1 & $2.0^{\star \star \star}$ & 1.5 to 2.6 \\
\hline $50-59$ & $4.6^{\star \star \star}$ & 3.6 to 5.9 & $5.3^{\star \star \star}$ & 4.0 to 6.9 & $2.4^{\star \star \star}$ & 1.9 to 3.1 & $3.2^{\star \star \star}$ & 2.4 to 4.2 \\
\hline$\geq 60$ & $4.2^{\star \star \star}$ & 3.2 to 5.6 & $4.9^{\star \star \star}$ & 3.5 to 6.9 & $2.7^{\star \star \star}$ & 2.1 to 3.5 & $3.7^{* \star \star}$ & 2.7 to 5.0 \\
\hline \multicolumn{9}{|l|}{ Gender } \\
\hline Male & Ref & & Ref & & Ref & & Ref & \\
\hline Female & $1.2^{*}$ & 1.0 to 1.4 & $1.3^{*}$ & 1.0 to 1.5 & $2.0^{\star \star \star}$ & 1.7 to 2.3 & $1.7^{\star \star \star}$ & 1.4 to 2.1 \\
\hline \multicolumn{9}{|l|}{ Educational status } \\
\hline No education & Ref & & Ref & & Ref & & Ref & \\
\hline Primary education & 1.1 & 0.9 to 1.4 & 1.3 & 1.0 to 1.7 & 0.9 & 0.7 to 1.1 & 1.1 & 0.9 to 1.4 \\
\hline Currently married & Ref & & NA & NA & Ref & & Ref & \\
\hline Others $^{*}$ & $1.6^{\star \star}$ & 1.2 to 2.1 & NA & NA & $2.8^{\star \star \star}$ & 2.2 to 3.6 & $1.8^{\star \star \star}$ & 1.3 to 2.4 \\
\hline \multicolumn{9}{|l|}{ Occupational status } \\
\hline Currently working & Ref & & Ref & & Ref & & NA & NA \\
\hline Currently not working & $3.1^{\star \star \star}$ & 2.1 to 4.4 & $1.7^{*}$ & 1.0 to 2.6 & $2.2^{\star \star \star}$ & 1.5 to 3.0 & NA & NA \\
\hline \multicolumn{9}{|l|}{ Religion } \\
\hline Islam & Ref & & NA & NA & Ref & & NA & NA \\
\hline Others $\dagger$ & $1.4^{*}$ & 1.1 to 1.9 & NA & NA & 1.1 & 0.6 to 1.8 & NA & NA \\
\hline \multicolumn{9}{|l|}{ Family type } \\
\hline Joint & Ref & & NA & NA & Ref & & NA & NA \\
\hline$<5$ servings per day & $0.7^{*}$ & 0.5 to 1.0 & NA & NA & 1.2 & 1.0 to 1.4 & NA & NA \\
\hline \multicolumn{9}{|l|}{ Added salt in diet } \\
\hline Yes & Ref & & NA & NA & Ref & & NA & NA \\
\hline No & 1.2 & 0.9 to 1.5 & NA & NA & $1.5^{\star \star}$ & 1.2 to 1.9 & NA & NA \\
\hline \multicolumn{9}{|l|}{ Physical activity } \\
\hline Adequate (MET $\geq 600$ per week) & Ref & & Ref & & Ref & & Ref & \\
\hline Inadequate (MET <600 per week) & $1.5^{\star \star \star}$ & 1.2 to 1.9 & $1.3^{*}$ & 1.0 to 1.7 & $1.9^{\star \star \star}$ & 1.6 to 2.4 & $1.5^{\star \star}$ & 1.2 to 1.9 \\
\hline \multicolumn{9}{|l|}{ Tobacco consumption } \\
\hline Yes & Ref & & Ref & & Ref & & Ref & \\
\hline No & $1.6^{\star \star \star}$ & 1.3 to 1.9 & $1.3^{*}$ & 1.0 to 1.6 & $1.5^{\star \star \star}$ & 1.3 to 1.8 & $1.4^{\star \star}$ & 1.2 to 1.7 \\
\hline \multicolumn{9}{|l|}{ Overweight or obesity } \\
\hline No & Ref & & Ref & & Ref & & Ref & \\
\hline Yes & $2.6^{\star \star \star}$ & 2.2 to 3.2 & $2.7^{\star \star \star}$ & 2.1 to 3.3 & $2.0^{\star \star \star}$ & 1.7 to 2.4 & $2.1^{\star \star \star}$ & 1.7 to 2.5 \\
\hline
\end{tabular}

${ }^{*} \mathrm{P}<0.05,{ }^{* *} \mathrm{p}<0.01,{ }^{* \star *} \mathrm{p}<0.001$.

$\mathrm{NA}=$ not applicable; these variables were dropped from the final model because of having $\mathrm{p}>0.1$ in the forward stepwise regression model.

Confounders: the odds of being hypertensive were adjusted for age, gender, educational status, occupational status, physical activity, tobacco consumption, overweight or obesity in urban areas. Similarly, the odds of being hypertensive were adjusted for age, gender, educational status, marital status, physical activity, tobacco consumption, overweight or obesity adjusted for confounding in rural areas.

*Never married, widows, divorced and separated.

tHindu, Christian, Buddhist and others.

MET, metabolic equivalent. 
urban-2.11 per 1000 people, rural-1.06 per 1000 population). ${ }^{37-39}$ The disproportionate internal migration rate prevailing between urban and rural Bangladesh might also play a role in this regard. According to the report titled 'Population Distribution and Internal Migration in Bangladesh', published in 2015, most rural to urban migrants occur in younger age groups ${ }^{40}$; and, migration of old age groups shows the opposite trend. ${ }^{41-44}$ However, further study, preferably using a longitudinal design, is warranted to understand this finding better. The prevalence of hypertension increases with age because of vascular resistance, which reduces the ability to resolve inflammation, raises cellular oxidative stress and endothelial dysfunction. ${ }^{45}$ Since Bangladesh is going through a demographic transition, the proportion of aged people is increasing rapidly. ${ }^{46}$ If the current trend continues, by 2050 , around 45 million elderly people will reside in Bangladesh ${ }^{46}$ and therefore, a large number of elderly people will be vulnerable to hypertension and other chronic diseases. Accordingly, the government of Bangladesh should develop strategies to prevent and control hypertension and its complications.

Urban residents who completed secondary or higher education had significantly higher odds of hypertension compared with those who received no education. We observed a similar finding in rural settings among only those who received higher education. This finding is coherent with a Bangladeshi study, which revealed that highly educated urban and rural respondents had higher odds of developing hypertension. ${ }^{14}$ On the other hand, an opposite trend was observed in developed countries, where less educated people are more prone to develop hypertension. ${ }^{47}{ }^{48}$ Highly educated people from a developing country might be habituated to perform less physical activity and consume a higher quantity of unhealthy food items such as red meat and processed food. ${ }^{49}$ To combat the situation, the governments in these countries need to take the necessary steps to raise awareness among educated people in urban and rural areas on the consequences of an unhealthy lifestyle and hypertension. Otherwise, the burden of hypertension will continue to rise and will continue to create a considerable burden on our health system.

We reported a positive association between inadequate physical activity and hypertension in both urban and rural areas. This finding is consistent with earlier studies published from Bangladesh and other developing countries. ${ }^{3450}{ }^{51}$ It is evident that inadequate physical activity is one of the major modifiable risk factors for cardiovascular diseases. ${ }^{52}$ According to the STEPS Survey 2018, the current prevalence of inadequate physical activity is 29.1\% in Bangladesh. ${ }^{6}$ Howevere in Bangladesh, those who are performing adequate physical activities are doing mostly work-related and transport-related physical activities. ${ }^{53}$ Yet, people are not accustomed to the culture of doing recreational physical activities in developing countries. $^{545}$ Therefore, pertinent stakeholders should take necessary steps to make people aware of the benefits of performing adequate physical activities to halt the hypertension burden in Bangladesh. The government can develop strategies for keeping enough free spaces in the workplace so that people can perform physical activities. There is also need for creating more green space, parks, low-cost gymnasium facilities and parks in urban residential areas, and playgrounds at school, college and universities.

In rural and urban areas, the odds of being hypertensive were also positively associated with overweight or obesity. Our study finding was similar to earlier published studies from both developing and developed countries. ${ }^{48} 5657$ Overweight and obesity are well-established modifiable risk factors for NCDs like hypertension.$^{58}$ Since the prevalence of overweight and obesity is increasing in Bangla$\operatorname{desh}^{53}$ it is anticipated that this existing high burden will further increase the risk of developing hypertension among Bangladeshi people. A population-based intervention for prevention and control of overweight and obesity is warranted to restrain the rising trend.

In our study, we reported that consumption of any form of tobacco was a protective factor for developing hypertension among study respondents. This result can be explained by the phenomenon called 'reverse causation', which means people might cease smoking tobacco after being diagnosed as hypertensive. A similar finding was reported by another study conducted in the Sylhet division of Bangladesh. ${ }^{34}$

\section{Strengths and limitations}

In Bangladesh, we found only one study that reported the prevalence and associated factors of hypertension in urban and rural areas. However, the study used data from the Bangladesh Demographic and Health Survey 2010, which did not have data on behavioural risk factors like fruits and vegetable consumption, physical activity and tobacco consumption. However, in this study used baseline data from SHASTO project conducted in 2018 and included data on behavioral factors e.g., fruits and vegetable consumption, physical activity and tobacco consumption along with a number of sociodemographic and metabolic factors. In our study, we also included a large sample from both the rural and urban areas, which enabled us perform sub-group analysis. This study also has some limitations. In our study, we collected blood pressure data on a single day for each participant and did not consider the 'white coat effect'. Since this is a crosssectional study, we could not establish causality due to the lack of temporal relationship. As this study was conducted in two urban and two rural sites of the Dhaka division; the findings might not be generalizable for the whole Bangladesh, especially in regions where the geographical and sociocultural variation is more than the same in Dhaka division. Theestimated sample size for this study was 4608 . However, considering the $10 \%$ non-response rate, the sample size was inflated to 5072 . We were finally able to collect data from 4930 respondents, which surpassed the required sample size without infalting for 
the non-response rate. The final sample size for this analysis iwas 4856 , which was again larger than the estimated sample size without considering the non-response rate. Another limitation is that we categorised a person as hypertensive if his/her systolic blood pressure is $\geq 140$ $\mathrm{mm} \mathrm{Hg}$ or diastolic blood pressure is $\geq 90 \mathrm{~mm} \mathrm{Hg}$, or diagnosed hypertensive by a professional healthcare provider. We did not use the medication variable to operationally define hypertension.

\section{CONCLUSION}

This study revealed reported the prevalence and associated factors of hypertension in selected urban and rural areas of Dhaka division, Bangladesh. The prevalence of hypertension is high in both urban and rural areas, but compared with rural areas, the prevalence of hyoertension is higher in urban areas for many sociodemographic, behavioural and metablic strata. There are some differences with respect to factors associated with hypertension dbetween the urban and rural areas. Therefore, the government of Bangladesh should customize the hypertension prevention and control interventions considering the factors associated with hypertension in both the areas. Primary prevention activities should also focus on people in relatively younger age group in both urban and rural areas. At the same time, community-based screening programmes should be carried out for early detection of hypertension and ensure proper management of hypertension for those who already developed the condition.

\section{Author affiliations}

${ }^{1}$ Centre for Non-communicable Diseases and Nutrition, BRAC University James P

Grant School of Public Health, Dhaka, Dhaka District, Bangladesh

${ }^{2}$ Centre for Science of Implementation and Scale-up, BRAC James P Grant School

of Public Health, BRAC University, Dhaka, Dhaka District, Bangladesh

${ }^{3}$ Japan International Cooperation Agency, Chiyoda-ku, Tokyo, Japan

${ }^{4}$ Department of Epidemiology and Research, National Heart Foundation Hospital and Research Institute, Dhaka, Bangladesh

Acknowledgements The authors acknowledge the Japan International Cooperation Agency (JICA) for providing them the fund to conduct this study. They also acknowledge their study participants and community people for their continuous support.

Contributors $\mathrm{MH}$ conceptualised, designed, implemented, analysed and prepared the first draft of the manuscript. MSAK, IS, MMH and MHe conceptualised, implemented and reviewed the drafts of the manuscript. YY, SRC and MS conceptualised, designed, reviewed and edited the drafts of the manuscript. MKM conceptualised, designed, supervised, reviewed and edited the drafts of the manuscript.

Funding The study was funded by the Japan International Cooperation Agency (JICA).

\section{Competing interests None declared.}

Patient and public involvement Patients and/or the public were not involved in the design, or conduct, or reporting, or dissemination plans of this research.

\section{Patient consent for publication Not required.}

Ethics approval Ethical approval for this study was obtained from the Institutional Review Board (IRB) of BRAC James P Grant School of Public Health, BRAC University, Dhaka, Bangladesh (reference no: 2018-009-IR).

Provenance and peer review Not commissioned but externally peer reviewed.
Data availability statement Data are available upon request. Data will be available upon request to IRB Chair, BRAC James P Grant School of Public Health, BRAC University, Dhaka, Bangladesh to the email address: kirb-jpgsph@bracu.ac. bd.

Open access This is an open access article distributed in accordance with the Creative Commons Attribution Non Commercial (CC BY-NC 4.0) license, which permits others to distribute, remix, adapt, build upon this work non-commercially, and license their derivative works on different terms, provided the original work is properly cited, appropriate credit is given, any changes made indicated, and the use is non-commercial. See: http://creativecommons.org/licenses/by-nc/4.0/.

\section{ORCID iDs}

Mehedi Hasan http://orcid.org/0000-0003-2153-4979

Malay Kanti Mridha http://orcid.org/0000-0001-9226-457X

\section{REFERENCES}

1 Fisher NDL, Curfman G. Hypertension-A public health challenge of global proportions. JAMA 2018;320:1757-9.

2 WHO. Hypertension, 2019. Available: https://www.who.int/news$\mathrm{room} /$ fact-sheets/detail/hypertension [Accessed 19 Nov 2019].

3 Kearney PM, Whelton M, Reynolds K, et al. Global burden of hypertension: analysis of worldwide data. Lancet 2005;365:217-23.

4 Sarki AM, Nduka CU, Stranges S, et al. Prevalence of hypertension in low- and middle-income countries: a systematic review and metaanalysis. Medicine 2015;94:e1959.

5 Ahsan Karar Z, Alam N, Kim Streatfield P. Epidemiological transition in rural Bangladesh, 1986-2006. Glob Health Action 2009;2:1904

6 NIPSOM. Bangladesh ncd risk factor survey 2018, 2020. Available: http://nipsom.gov.bd/pdf/Bangladesh_NCD_Risk_Factor_Survey_ 2018_STEPS_Result_Factsheet.pdf [Accessed 12/01/2020].

7 Conen D, Glynn RJ, Ridker PM, et al. Socioeconomic status, blood pressure progression, and incident hypertension in a prospective cohort of female health professionals. Eur Heart J 2009;30:1378-84.

8 Erceg M, Kern J, Babić-Erceg A, et al. Regional differences in the prevalence of arterial hypertension in Croatia. Coll Antropol 2009;33 Suppl 1:19-23.

9 Levine DA, Lewis CE, Williams OD, et al. Geographic and demographic variability in 20-year hypertension incidence: the cardia study. Hypertension 2011;57:39-47.

10 Commodore-Mensah Y, Samuel LJ, Dennison-Himmelfarb CR, et al. Hypertension and overweight/obesity in Ghanaians and Nigerians living in West Africa and industrialized countries: a systematic review. $J$ Hypertens 2014;32:464-72.

11 Kavishe B, Biraro S, Baisley K, et al. High prevalence of hypertension and of risk factors for non-communicable diseases (NCDS): a population based cross-sectional survey of NCDS and HIV infection in northwestern Tanzania and southern Uganda. BMC Med 2015;13:126.

12 Okpechi IG, Chukwuonye II, Tiffin N, et al. Blood pressure gradients and cardiovascular risk factors in urban and rural populations in Abia state South Eastern Nigeria using the who stepwise approach. PLOS One 2013;8:e73403.

13 Oladapo OO, Salako L, Sodiq O, et al. A prevalence of cardiometabolic risk factors among a rural Yoruba south-western Nigerian population: a population-based survey. Cardiovasc J Afr 2010;21:26.

14 Kibria GMA, Swasey K, Das Gupta R, et al. Differences in prevalence and determinants of hypertension according to rural-urban place of residence among adults in Bangladesh. $J$ Biosoc Sci 2019;51:578-90.

15 Cogill B. Anthropometric indicators measurement guide, 2001.

16 Maldonado G, Greenland S. Simulation study of confounderselection strategies. Am J Epidemiol 1993;138:923-36.

17 Victora CG, Huttly SR, Fuchs SC, et al. The role of conceptual frameworks in epidemiological analysis: a hierarchical approach. Int $J$ Epidemiol 1997;26:224-7.

18 Kutner MH, Nachtsheim CJ, Neter J. Applied linear statistical mode/s. New York: McGraw-Hill Irwin, 2005.

19 StataCorp L. Stata survival analysis reference manual, 2017.

20 Chowdhury MAB, Uddin MJ, Haque MR, et al. Hypertension among adults in Bangladesh: evidence from a national cross-sectional survey. BMC Cardiovasc Disord 2016;16:22.

21 Atkinson K, Lowe S, Moore S. Human development, occupational structure and physical inactivity among 47 low and middle income countries. Prev Med Rep 2016;3:40-5.

22 Martin SL, Kirkner GJ, Mayo K, et al. Urban, rural, and regional variations in physical activity. $J$ Rural Health 2005;21:239-44. 
23 Bishwajit Get al. Trade liberalization, urbanization and nutrition transition in Asian countries. J Nutrit Health Food Sci 2014;2:5.

24 Zvar Hurtig R. Food habit transitions in the urban areas of lowincome countries: a study on how globalization and urbanization influence food habits among primary pupils in Babati town, Tanzania, 2009.

25 Liu H, Walker GJ. The Effects of Urbanization, Motivation, and Constraint on Chinese People's Leisure-Time Physical Activity. Leisure Sciences 2015;37:458-78.

26 Srivastava K. Urbanization and mental health. Ind Psychiatry J 2009;18:75

27 Sobngwi E, Mbanya J-CN, Unwin NC, et al. Physical activity and its relationship with obesity, hypertension and diabetes in urban and rural Cameroon. Int J Obes Relat Metab Disord 2002;26:1009-16.

28 Spruill TM. Chronic psychosocial stress and hypertension. Curr Hypertens Rep 2010;12:10-16.

29 Zhao M, Konishi Y, Glewwe P. Does information on health status lead to a healthier lifestyle? Evidence from China on the effect of hypertension diagnosis on food consumption. J Health Econ 2013;32:367-85

30 Awal M, Sabur SA, Mia M. Estimation of vegetable demand elasticities in Bangladesh: application of almost ideal demand system model. Bangladesh Journal of Agricultural Economics 2008;31:35-60.

31 Huq A, Arshad F. Demand elasticities for different food items in Bangladesh. Journal of Applied Sciences 2010;10:2369-78.

32 Alam MJ, Hossain MA. Motivations behind attending fitness clubs in Bangladesh: A survey study on clubs' members in Sylhet. World2012;4.

33 Khan A, Burton NW, Trost SG. Patterns and correlates of physical activity in adolescents in Dhaka City, Bangladesh. Public Health 2017;145:75-82.

34 Khanam R, Ahmed S, Rahman S, et al. Prevalence and factors associated with hypertension among adults in rural Sylhet district of Bangladesh: a cross-sectional study. BMJ Open 2019;9:e026722.

35 Shafi ST, Shafi T. A survey of hypertension prevalence, awareness, treatment, and control in health screening camps of rural central Punjab, Pakistan. J Epidemiol Glob Health 2017;7:135-40.

36 Tripathy JP, Thakur JS, Jeet G, et al. Alarmingly high prevalence of hypertension and pre-hypertension in North India-results from a large cross-sectional steps survey. PLoS One 2017;12:e0188619.

37 Burkart K, Schneider A, Breitner S, et al. The effect of atmospheric thermal conditions and urban thermal pollution on all-cause and cardiovascular mortality in Bangladesh. Environ Pollut 2011;159:2035-43.

38 Islam M. PP-241 mortality and epidemiological transition in Bangladesh: lessons and experiences to the developing countries in the new millennium. International Journal of Infectious Diseases 2010;14:S97-8

39 Sarkar ASR, Islam N, Hoque A. Cause and age-related mortality trends in Bangladesh (2000-2008). F1000Res 2017;6:210.

40 BBS. Population distribution and internal migration in Bangladesh. Government of the People's Republic of Bangladesh Dhaka, 2015.
41 Islam MN, Nath DC. A future journey to the elderly support in Bangladesh. Journal of Anthropology 2012;2012:1-6.

42 Kuhn R. The impact of nuclear family and individual migration on the elderly in rural Bangladesh: a qualitative analysis: Rand CORP SANTA MONICA Ca, 2001.

43 Marshall R, Rahman S. Internal migration in Bangladesh: character, drivers and policy issues. New York: United Nations Development Programme (UNDP, 2013.

44 Rural-Urban migration in Bangladesh: a micro-level study. Brazil IUSSP conference August 2001.

45 Buford TW. Hypertension and aging. Ageing Res Rev 2016;26:96-111.

46 Islam MM. Demographic transition and the emerging windows of opportunities and challenges in Bangladesh. J Popul Res 2016;33:283-305.

47 Sampson UKA, Edwards TL, Jahangir E, et al. Factors associated with the prevalence of hypertension in the southeastern United States: insights from 69,211 blacks and whites in the southern community cohort study. Circ Cardiovasc Qual Outcomes 2014;7:33-54.

48 Seow LSE, Subramaniam M, Abdin E, et al. Hypertension and its associated risks among Singapore elderly residential population. Journal of Clinical Gerontology and Geriatrics 2015;6:125-32.

49 Fan M, Su M, Tan Y, et al. Gender, age, and education level modify the association between body mass index and physical activity: a cross-sectional study in Hangzhou, China. PLoS One 2015;10:e0125534.

50 Bhadoria AS, Kasar PK, Toppo NA, et al. Prevalence of hypertension and associated cardiovascular risk factors in central India. J Family Community Med 2014;21:29.

51 Islam SMS, Mainuddin A, Islam MS, et al. Prevalence of risk factors for hypertension: a cross-sectional study in an urban area of Bangladesh. Glob Cardiol Sci Pract 2015;2015:43.

52 Lawes CMM, Vander Hoorn S, Rodgers A et al. Global burden of blood-pressure-related disease, 2001. Lancet 2008;371:1513-8.

53 Zaman MM, Bhuiyan MR, Karim MN, et al. Clustering of noncommunicable diseases risk factors in Bangladeshi adults: an analysis of steps survey 2013. BMC Public Health 2015;15:659.

$54 \mathrm{Ku}$ P-W, Fox KR, McKenna J, et al. Prevalence of leisure-time physical activity in Taiwanese adults: results of four national surveys, 2000-2004. Prev Med 2006;43:454-7.

55 Trinh OTH, Nguyen ND, Dibley MJ, et al. The prevalence and correlates of physical inactivity among adults in Ho Chi Minh City. BMC Public Health 2008;8:1-11.

56 Bjertness MB, Htet AS, Meyer HE, et al. Prevalence and determinants of hypertension in Myanmar - a nationwide cross-sectional study. BMC Public Health 2016;16:590.

57 Hasan M, Sutradhar I, Akter T, et al. Prevalence and determinants of hypertension among adult population in Nepal: data from Nepal demographic and health survey 2016. PLoS One 2018;13:e0198028.

58 Aronow WS. Association of obesity with hypertension. Ann Trans/ Med 2017;5:350. 